\title{
GEODETIC ACTIVITIES FOR EARTHQUAKE PREDICTION BY GEOGRAPHICAL SURVEY INSTITUTE, JAPAN: EXTENDED ABSTRACT
}

\author{
Noboru INOUYE \\ Observation Division, Crustal Dynamics Department, \\ Geographical Survey Institute, \\ Ministry of Construction, Ibaraki, Japan \\ (Received May 1, 1985)
}

\section{Introduction}

The Geographical Survey Institute (G.S.I.) is a government office responsible for making modern maps. It has been issuing $1 / 50,000$-scale topographic maps as national basic maps for about 100 years. Therefore, geodetic works also have a 100 -year-old history in Japan.

As the first nationwide geodetic surveys in Japan, a base line survey was commenced in 1882 and triangulations and leveling in 1883. And in 1913 they were completed in main land Japan.

Besides these surveys, recovery geodetic surveys were carried out just after some earthquakes, like the Mino-Owari (Nobi) earthquake in 1891 and the Great Kanto earthquake in 1923.

Periodically repeated geodetic surveys for earthquake prediction were planned and made from the 1960s and every result with strain in the crust has soon been reported to the Coordinating Committee for Earthquake Prediction held four times a year.

Great efforts to devise more efficient ways of surveying and to produce higher precision of the results have been made.

\section{Ordinary Repetition Surveys}

Following a base line survey in 1882 , the first nationwide triangulation surveys for modern mapping were started in 1883. The surveys covered about 990 first-order and supplementary first-order triangulation stations, between which the mean distance is about $25 \mathrm{~km}$, and finished in 1913 at Hokkaido mainly by angular measurements.

Taking a recovery survey after the 1946 Nankai earthquake, the second nationwide triangulation surveys were started in 1949. The way of the second surveys differed from that of the first one; they contained many Laplace observations (astronomical observations and direction observations) and measured many distances between triangulation stations directly. They were completed in 1967.

The third nationwide surveys were started in 1968 from the southern part of Japan, 
with a view to earthquake prediction. But they were discontinued in 1973 at central Japan because the results from distance surveys by electronic distance measuring instruments yielded higher accuracy.

In 1974, the new nationwide surveys of trilaterations in which the mean distance is about $8 \mathrm{~km}$ by electronic distance measuring instruments, were started for earthquake prediction. This is called "The Precise Geodetic Network Survey" in Japan. They were finished in the fiscal year of 1985 for the first time and the second one is started.

On the other hand, the nationwide first-order leveling routes of about $20,000 \mathrm{~km}$ were firstly observed from 1883 and observations were completed in 1913 at Hokkaido similar to triangulations.

The second first-order leveling surveys were started just after the 1923 Great Kanto earthquake and ended in 1945.

Surveys which were originally recovery surveys for the Nankai earthquake in 1946, became country wide for investigating the earthquake deformation; this third nationwide leveling was completed in 1961.

In 1962, the fourth began for earthquake prediction and ended in 1971. Following these, the fifth and sixth were done by five-year cycles except Hokkaido. And now the seventh nationwide leveling, which will be completed in 1987, is under operation from southern to central Japan.

Furthermore, tidal stations which measure sea levels and lead the standard of height were constructed one after another from the 1890s. Now 23 G.S.I. tidal stations are functioning. First-order leveling routes are connected to these stations.

\section{Recovery Surveys}

Besides ordinary repetition surveys, many large or small recovery surveys were performed after earthquakes such as the Mino-Owari (Nobi) earthquake in 1891, the Sakurajima (Eruption) earthquake in 1914, the Great Kanto earthquake in 1923, the Tango earthquake in 1927, the Kita-Izu earthquake in 1930, the Tottori earthquake in 1943, the Nankai earthquake in 1946, the Fukui earthquake in 1948, the Niigata earthquake in 1964, the Matsushiro earthquake swarm from 1965, the Miyagi-oki earthquake in 1978 , etc.

For example, after the Nankai earthquake, its extensive recovery survey covered 173 first-order triangulation stations and $3,526 \mathrm{~km}$ of leveling routes.

Artificial subsidence, caused by underground water's being pumped up, had been surveyed every year in the 1960s on Niigata Plain by leveling. These data with the recovery surveys' data happened to catch anomalous vertical movements of the ground before and after the Niigata earthquake in 1964 (see DamBARA, 1973). This was a remarkable event which made us confident that geodetic surveys are a powerful means of earthquake prediction.

\section{Nationwide Geodetic Surveys for Earthquake Prediction}

The Geodesy Council, Ministry of Education, submitted the second proposal entitled 
"Enforcement of Earthquake Prediction Research Plan" to the Ministers concerned in 1964. At the same time, it was clearly declared in the Second Basic Survey Long-Term Plan of G.S.I. that "one of the purposes of geodetic surveys is to get basic data for earthquake prediction." In the Second Plan, the period of repetition surveys of nationwide triangulation or trilateration was 15 years and that of first-order leveling was 10 years. In the Third Plan from 1974, both of these were 5 years and leveling was done along the Plan, but that of trilaterations required 10 years because of rising costs and budget constraints.

Furthermore, gravity and geomagnetic surveys are carried out through out the country for research on their distributions and crustal structures; results yield valuable information for earthquake prediction.

\section{Special Area Surveys}

In 1970, the Coordinating Committee for Earthquake Prediction appointed special areas, those are, "areas of specific observation" where several repetition surveys should be more strongly promoted than in the rest of the country and "areas of intensified observation" where surveys are much more strongly promoted when abnormal crustal movements are detected (Fig. 1). In these areas repetition geodetic surveys with shorter periods than nationwide ones have been carried out. And in the Third Plan, additional leveling of 5-year repetition and distance surveys of 6.6-year repetition were scheduled. Together with nationwide surveys, leveling was to be repeated every 2.5 years and distance surveys were every 3 years in these areas.

Beyond the Plan, earthquake prediction is to be put to practical use; therefore, in the areas of intensified observation, i.e., Metropolis, Boso Peninsula, Miura Peninsula, Izu Peninsula, and Tokai district, leveling and distance surveys have been done by shorter periods from 1975.

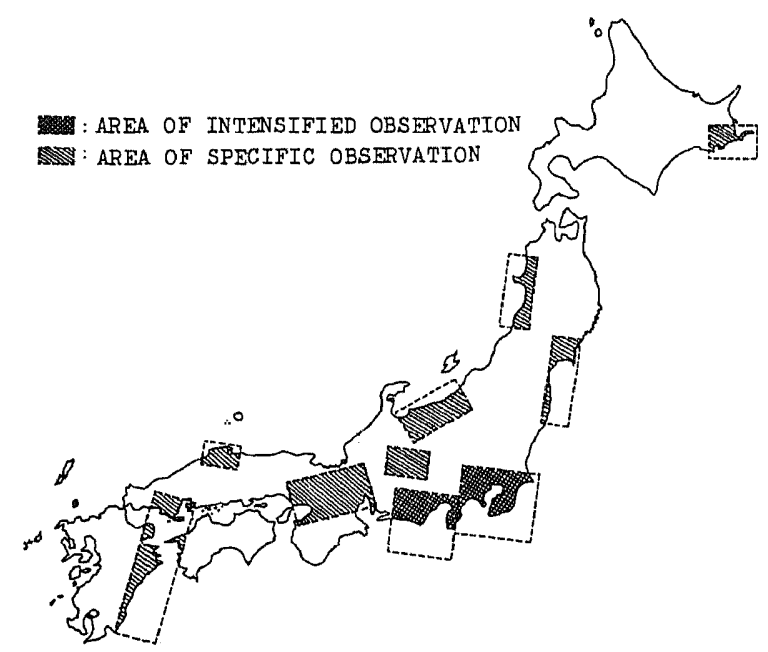

Fig. 1. Area of specific observation and area of intensified observation. 


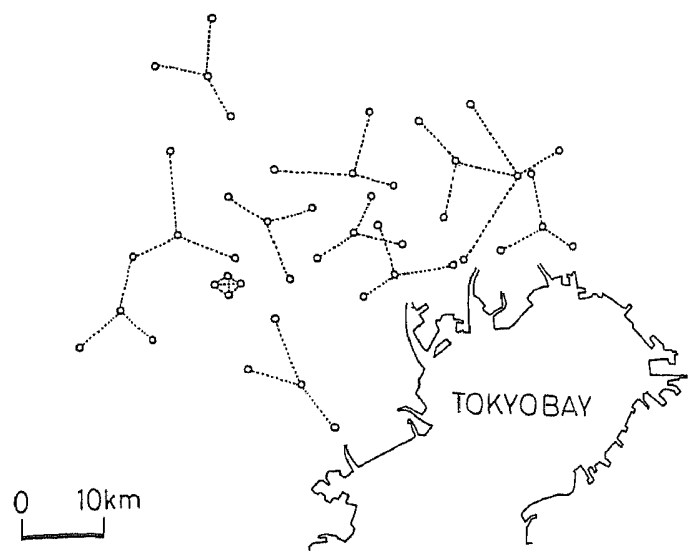

Fig. 2. Precise crustal strain detection survey in Tokyo Metropolitan area.

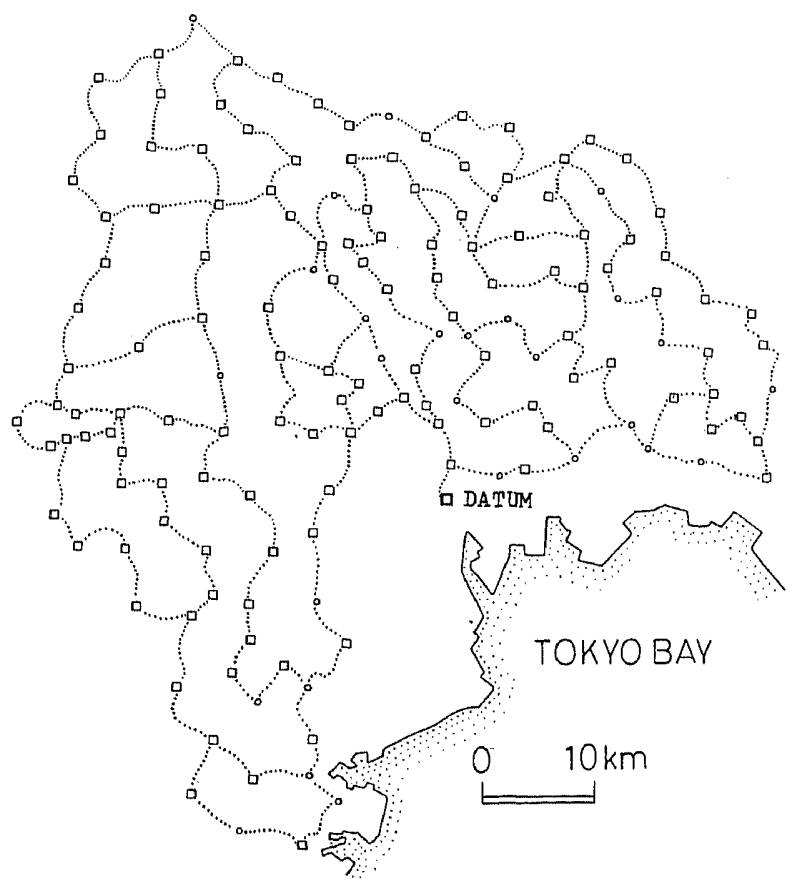

Fig. 3. Bedrock tilting detection survey in Tokyo Metropolitan area.

In Tokyo Metropolitan area, precise distance measurements along short rhombus base lines and radial base lines, named "Precise Crustal Strain Detection Survey," are performed every 2 years (Fig. 2). Also, precise levelings, named "Bedrock Tilting Detection Surveys," are repeated every year or with a period of 2 years (Fig. 3). Benchmarks of this leveling net have $10 \mathrm{~m}$ or more lengths into the ground to catch not a surface but bedrock 


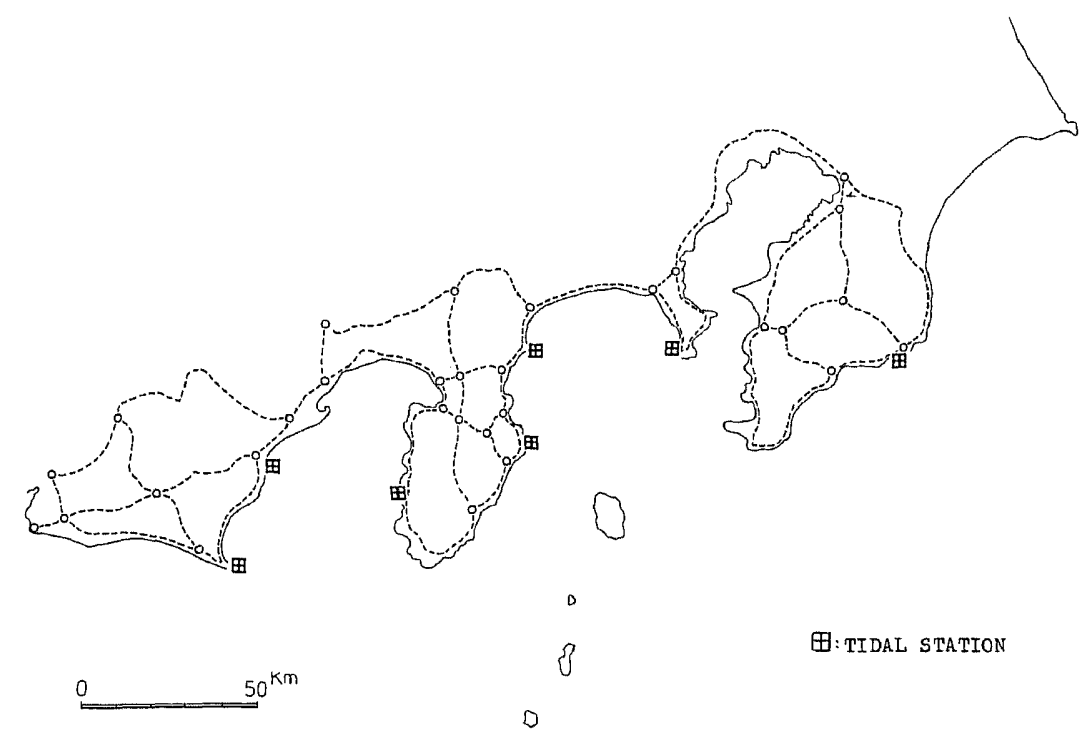

Fig. 4. Precise leveling routes in Boso, Miura, and Izu Peninsulas and Tokai district.

movement. And a sight length in the leveling is limited to less than $40 \mathrm{~m}$, which is less than $50 \mathrm{~m}$ for nationwide leveling. Height difference between forward observation and backward are limited by $2 \sqrt{s}$, where unit is millimeter and $s$ is a distance between benchmarks in kilometers, which is $2.5 \sqrt{s}$ for nationwide leveling.

In Boso, Miura, and Izu Peninsulas and Tokai district, precise levelings with a sight length of less than $40 \mathrm{~m}$ and difference limitation of $2 \sqrt{s}$ are carried out once or twice a year (Fig. 4).

In Izu Peninsula, it is thought many crustal movements which were associated with earthquakes had been observed. The 1976 Kawazu earthquake (M 5.4) occurred after a 15 $\mathrm{cm}$ upheaval was observed near Hiekawa Pass. The 1978 Izu-Oshima earthquake (M7.0) hit after an upheaval stop near the Pass. In 1978 and 1979, re-upheaval near the Pass and upheaval near Ito with small earthquake swarm near Kawazu were observed. The 1980 Izu (Izu-Toho-Oki) earthquake ( $M$ 6.7) and earthquake swarms hit after upheaval stop near Ito and Hiekawa Pass. The 1982 Izu-Oshima earthquake (M 5.7) followed upheaval and slow re-upheaval near Ito.

And in Omaezaki, where it is said that a great earthquake might hit in the not so distant future, leveling is repeated 4 times a year, and seasonal variation with subsidence tendency has been detected.

And cluster observations composed of precise distance surveys and leveling are made once or twice a year. The observations are done at 5 places, where there are 4 or 5 geodetic stations in Izu Peninsula and Tokai district (Fig. 5).

Precise crustal strain detection surveys over Sagami Bay surrounded by Izu, Miura, Boso Peninsulas, and Izu-Oshima Island and over Suruga Bay surrounded by Izu Peninsula and Tokai district are alternately done every year. And in the northern part of 

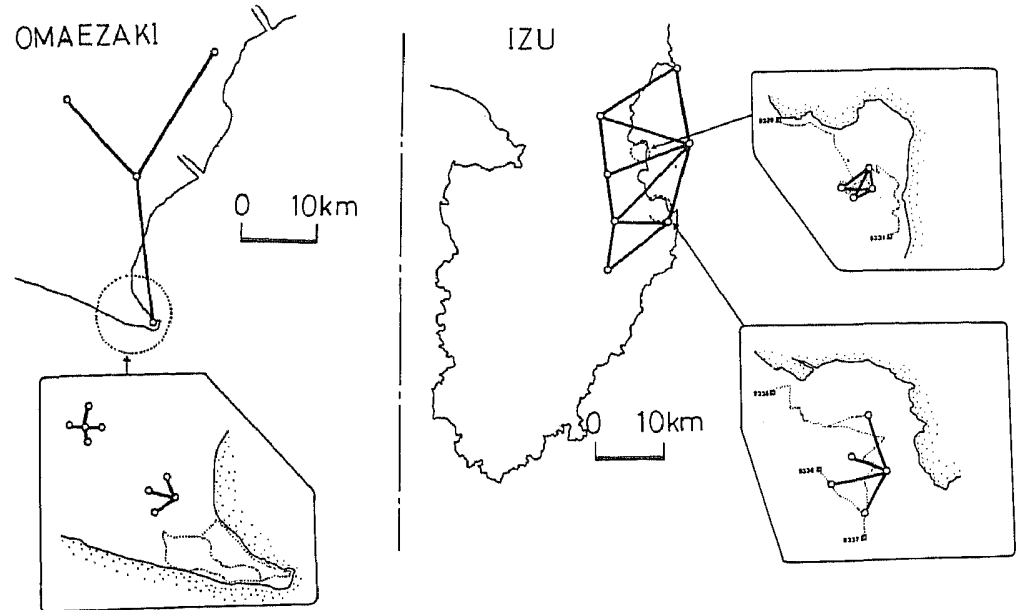

Fig. 5. Cluster observation areas.

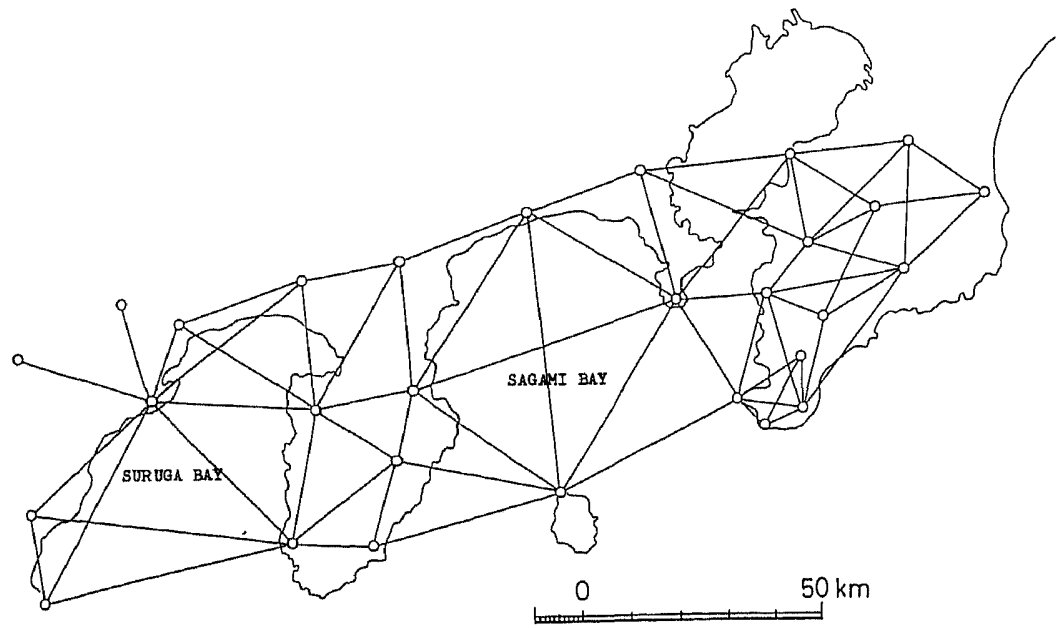

Fig. 6. Precise crustal strain detection surveys over Sagami Bay and Suruga Bay.

Izu Peninsula, the same survey with shorter length is repeated every year (Fig. 6).

Other specific observation areas have their own short base lines which are observed once a year or two years. Among them there are some short or rhombus base lines across presumed active faults.

\section{New Methods and Instruments}

The method of horizontal movement detection survey changed from angular measurements to mainly distance measurements 10 years ago.

As is well known, a result from an electronic distance measuring instrument is affected 


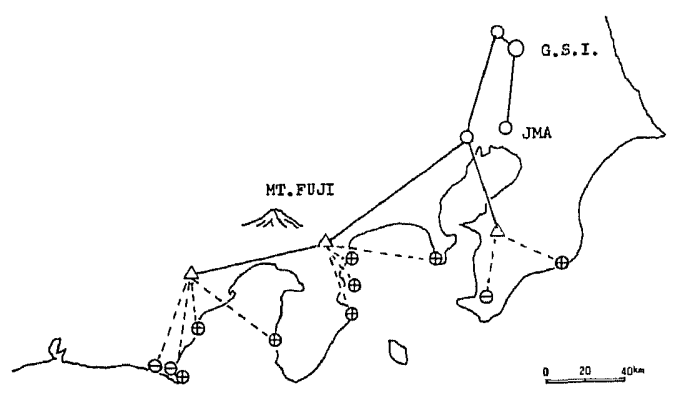

Fig. 7. Telemetering network. The circles with plus and those with minus indicate tidegauge stations and strain or tilt stations, respectively.

by meteorological conditions along a light path; it is thus thought to be impossible to get real-time data. And after many trials, it was tentatively decided that in G.S.I.'s fieldwork, distances would be measured within $2 \mathrm{~h}$ before and after sunset, and the measured distances would be corrected by mean meteorological conditions at both an instrument point and a reflection mirror point.

G.S.I. was not satisfied with this uncertainty and made efforts to develop a new portable distance measuring instrument with multi-colors which observes distance and meteorological conditions simultaneously to get a higher precision result. Two carriers with different wavelengths - red light from a $\mathrm{He}-\mathrm{Ne}$ laser, blue from a $\mathrm{He}-\mathrm{Cd}$ laser-make differences in raw results. Meteorological correction to obtain a correct distance can be computed from the different raw results.

Another high precision electronic distance measuring instrument named Mekometer ME-3000 is employed at a short rhombus base line or radiant base line about $1 \mathrm{~km}$ long. When in operation, a modulation signal from the instrument is always compared with a signal from the standard oscillator to get more accurate results.

A several thousand kilometer distance is able to be measured with the accuracy of several centimeters by observing radio signals from quasars which are several hundred million light-years away from the earth. This method, whose system is called "Very Long Base Line Interferometer," may detect plate movements useful for earthquake prediction. In 1981, G.S.I. began to develop the system in cooperation with the Radio Research Laboratories, Ministry of Post and Telecommunication of Japan.

Though the fundamental way of leveling at field did not change too much, automatic compensator leveling instruments and electronic field notes e.g. small desk top calculators replacing field notes have recently been introduced to the nationwide leveling by the Geodetic Department in G.S.I. But a compensator leveling instrument is not used for the survey in the areas of specific observation yet, because the Crustal Dynamics Department in G.S.I. is not confident that it fits the survey. Inspection of leveling staffs is done efficiently by a laser interferometer.

Sometimes there is height-dependent error in leveling. It seems that height difference changes at two points in time correlate to the terrain profile. The refraction errors by temperature gradient near the ground, and scaling errors on leveling staffs are thought to 
be main causes. So G.S.I.'s tentative leveling surveys by new super invar staffs of very small coefficient of expansion with temperature are in progress. An interim report says that there is no need to apply refraction correction to the survey results in winter.

Data from 6 tidal stations, which are in the area of intensified observation, are transmitted to the main office by telemetering system ten times an hour (Fig. 7). So far, the rest of the tidal stations will be telemeterized by 1986 .

G.S.I. makes other observations which are effective in earthquake prediction, similar to geodetic surveys. Observations by extensometers in place of distance surveys and by water tube tiltmeter in place of leveling are carried out at Tateyama, Boso Peninsula, and at Omaezaki. They are also telemeterized (Fig. 7).

\section{REFERENCE}

Dambara, T., Crustal movements before, at and after the Niigata earthquake, Rep. Coord. Comm. Earthq. Predict., 9, 93-96, 1973 (in Japanese). 